\title{
Starch residues on grinding stones in private collections: a study of morahs from the tropical rainforests of NE Queensland
}

\author{
Judith Field ${ }^{1}$, Richard Cosgrove ${ }^{2}$, Richard Fullagar ${ }^{3}$ and Braddon Lance ${ }^{4}$ \\ 1. Australian Key Centre for Microscopy and Microanalysis, F09 and \\ School of Philosophical and Historical Inquiry \\ The University of Sydney \\ N.S.W. 2006 Australia \\ Email: judith.field@emu.usyd.edu.au \\ 2. Archaeology Program, School of Historical and European Studies \\ La Trobe University \\ Victoria 3086 Australia \\ 3. Scarp Archaeology \\ 25 Balfour Rd \\ Austinmer, NSW 2515 Australia \\ 4. Department of Statistics \\ Macquarie University \\ North Ryde NSW 2109 Australia
}

\begin{abstract}
Morahs are incised grinding stones from the tropical rainforests of Far North Queensland. They are made from grey slate, are roughly ovate to rectangular in shape, and have distinctive incised parallel grooves running transversely across the body of the stone. The region in which they are found is also known for the processing of toxic starchy plants by Aborigines. The process involves a relatively complex processing schedule, including cooking, pounding and leaching before consumption. Ethnographic studies have documented the processing of a number of rainforest species with starchy kernels in which morahs may have been used for pounding these kernels before leaching. A selection of morahs from private collections were analysed to determine their potential for starch residue studies. The results show that incised grooves act as residue traps for starch. In some cases the starch recovered from these grindstones enabled starch identifications of economically important endemic rainforest species, particularly Beilschmiedia bancroftii (Yellow walnut) and Endiandra insignis (Hairy_Walnut). The uneven surface created by the incised grooves may facilitate the breakup of the starchy kernels, and this proposal is supported by use-wear studies on similar artefacts where soft plant processing is indicated.
\end{abstract}

\section{KEYWORDS}

morah, grindstone, slate, starch residues, North Queensland rainforests, archaeology

\section{INTRODUCTION}

Grindstones from Australia are known to be used for a variety of functions including plant processing, preparation of ochre and also for the maceration of foods such as lizards and cats 
(Gould 1980; Mitchell 1848). Grindstones are ubiquitous in the more arid parts of the Australian continent where they are generally manufactured from sandstone and are associated with grass seed grinding (Fullagar and Field 1997; Fullagar et al. 2008; Smith 1985; Tindale 1977). Grindstones are also common in the tropical rainforests of far North Queensland and have often been found by farmers ploughing paddocks (Woolston \& Colliver 1973). One grindstone fragment has also been recovered from an occupation horizon excavated at Urumbal Pocket at Koombooloomba Dam in the Wet Tropics World Heritage Area (Cosgrove et al. 2007). One particular type of grindstone, referred to as the morah stone, comes from a well defined area from Tully in the south, to Cairns in the north and west to the Ravenshoe area on the Atherton Tablelands (Woolston and Colliver 1973:117; see Figure 1).

Morah stones (sometimes referred to as graters by locals) are made from grey slate, a soft and brittle stone that is available locally. They are distinguished from other grindstones by a series of incised grooves running perpendicular to the axis of the artefact (Figure 2). Maisie Barlow, a Jirrbal elder from Ravenshoe, relates that the incised grooves were made with quartz pieces, though bone points have also been suggested as tools for this purpose.

Morah stones occur in a region where the processing of toxic starchy plants is common (see Pedley 1993), and their use may be tied to the extended processing of these economically important foods. Morah stones are described by an unidentified Nutjen (Ngatjin) woman to be used

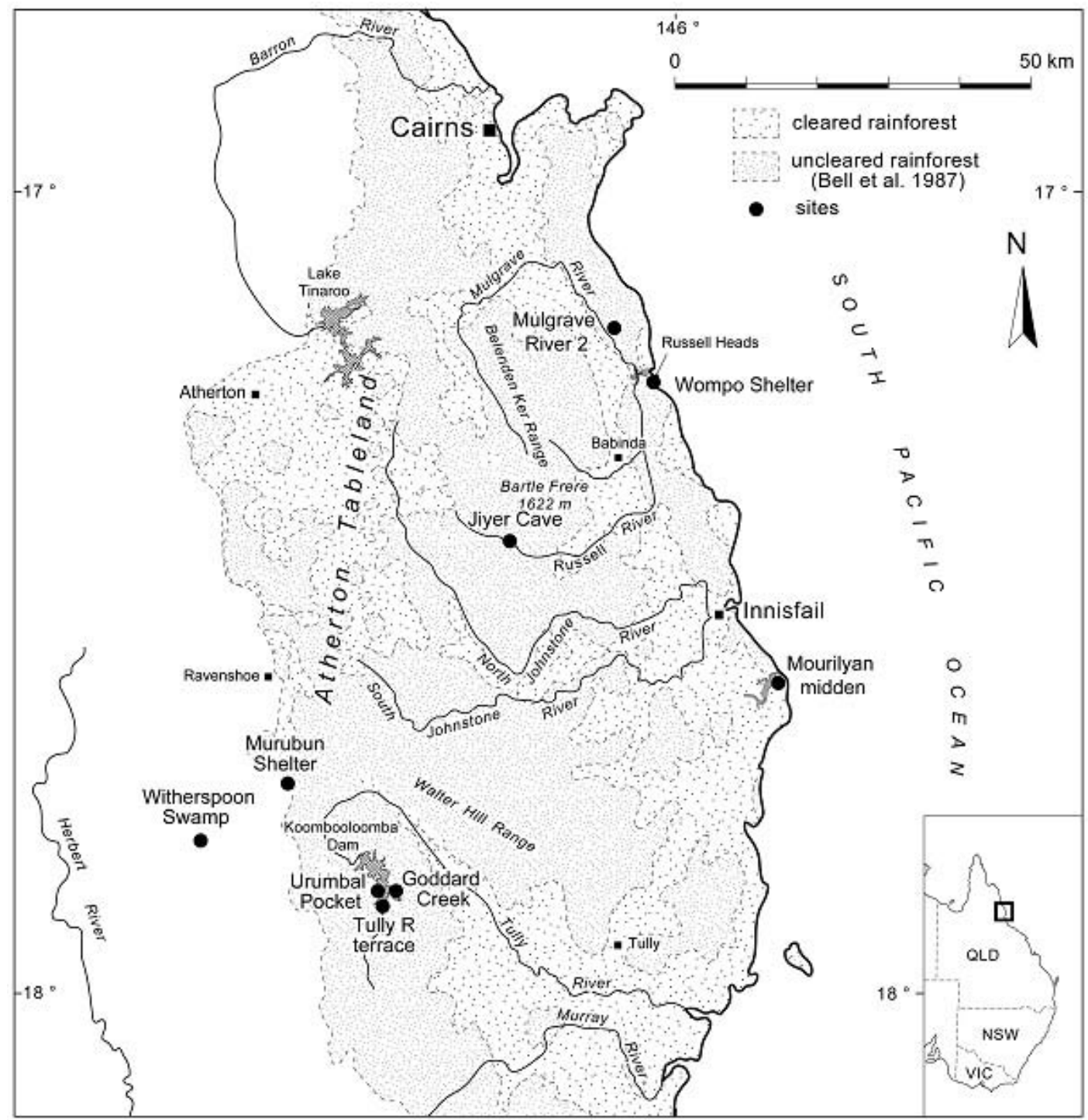

Figure 1. The study area in far North Queensland showing places mentioned in text. (Illustration: R. Frank, after Cosgrove et al., 2007). 


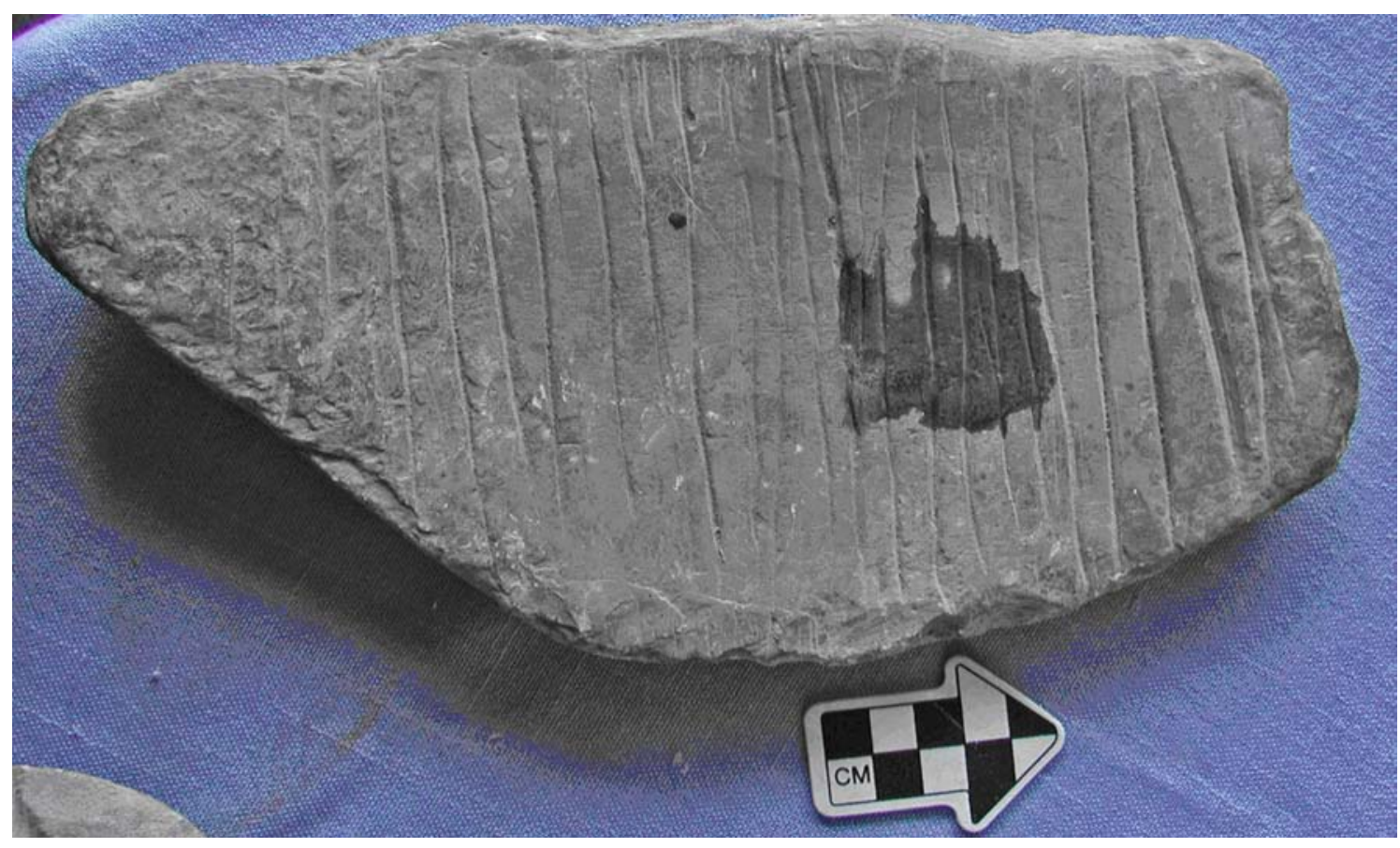

Figure 2. Incised slate grinding stone fragment from North Queensland. Darker patch in centre right of the grindstone is the location where the residue sample was collected. Note the parallel grooves running across the stone surface. Damage to the far left end of the stone is likely to be the result of damage from tractor blades prior to recovery. (Photo: J. Field, Courtesy of Pat and Alverio Croatto).

in a 'rolling crushing' motion rather than grinding (Woolston \& Colliver 1973). These were said to be used to crush zamia and walnuts. Apart from these two references, the use of morahs has not been documented elsewhere, either in the early explorer journals or in ethnographic records about the area (e.g. Ferrier 1999:80). Harris (2006:S69) has claimed that their use for pounding toxic plants is supported by 'testimony of Aboriginal people who retained knowledge of their former use'. The upper stones are known as 'moogi', the name given by the same informant describing the use of morahs referred to by Woolston and Colliver (1973:118) and are documented in the Australian and Queensland Museum collections. Moogi are usually a granite raw material, which are much harder than the slate of the morah stones.

Horsfall (1987:209-211) measured over 58 morahs (22 whole and 36 fragments) and found that none of them were more than $65 \mathrm{~mm}$ thick, though in this study the thickness of the grindstones did not exceed $30 \mathrm{~mm}$. The thickness of the grinding stones is argued to be a function of the slate raw material, which tends to cleave into relatively thin plates. Some of the morahs examined by Horsfall had incised grooves on both surfaces but most had incisions on only one surface. Used surfaces tend to be flat to concave, consistent with documented grindstone wear patterns (see Field \& Fullagar 1998; Smith 1985). Very few complete morahs are known and the largest morah we have observed was nearly $50 \mathrm{~cm}$ in length, and while broken, was mostly complete and in a private collection near Innisfail. Morahs are also known from the tablelands and recent surveys identified numerous examples during a survey of the foreshores of Koombooloomba Dam at low water levels, which is adjacent to the now flooded channels of the Tully River (Cosgrove et al. 2007; see Figure 1).

This paper presents the results of a study examining residue preservation on incised slate grinding stones (morahs) from the Far North Queensland rainforest that are held in private collections. Combined with overall morphology and related use-wear studies, the function of morah stones will be discussed. 


\section{METHODS}

The artefacts examined in this study were in private collections held at Innisfail and Babinda - on the coastal strip south of Cairns. The artefacts were generally stowed under houses or in sheds. These artefacts were collected by farmers when they were turned up during ploughing of fields in preparation for planting sugar cane. As such, some have been damaged and some had been refitted and glued together. Residue samples were generally collected in the field at the site where the collections were held.

Unused surfaces were smooth and featureless and not incised. Ethnographic observations of the processing of starchy foods indicate that all surfaces of the grindstone will generally become covered in starchy material (e.g. Figure 3) and any flaws, or incised surfaces are likely to act as residue traps. Combined with residue studies and morphological analyses, use-wear analysis is an informative adjunct for identifying patterns of wear and probable tasks (Fullagar et al. 1996). As use-wear analyses were not possible for these particular artefacts, the outcome of the analysis of similar artefacts by Richard Fullagar is used for comparison.

Eleven artefacts were sampled using a variable volume pipette to dispense c. $200 \mu$ aliquots of distilled water to the used surface of the grindstone. A nylon pipette tip was used to scrape along the incised grooves to dislodge residues. The water plus residue was then transferred to a $1.5 \mathrm{ml}$ microcentrifuge tube for transport back to the laboratory. As the size of the samples was

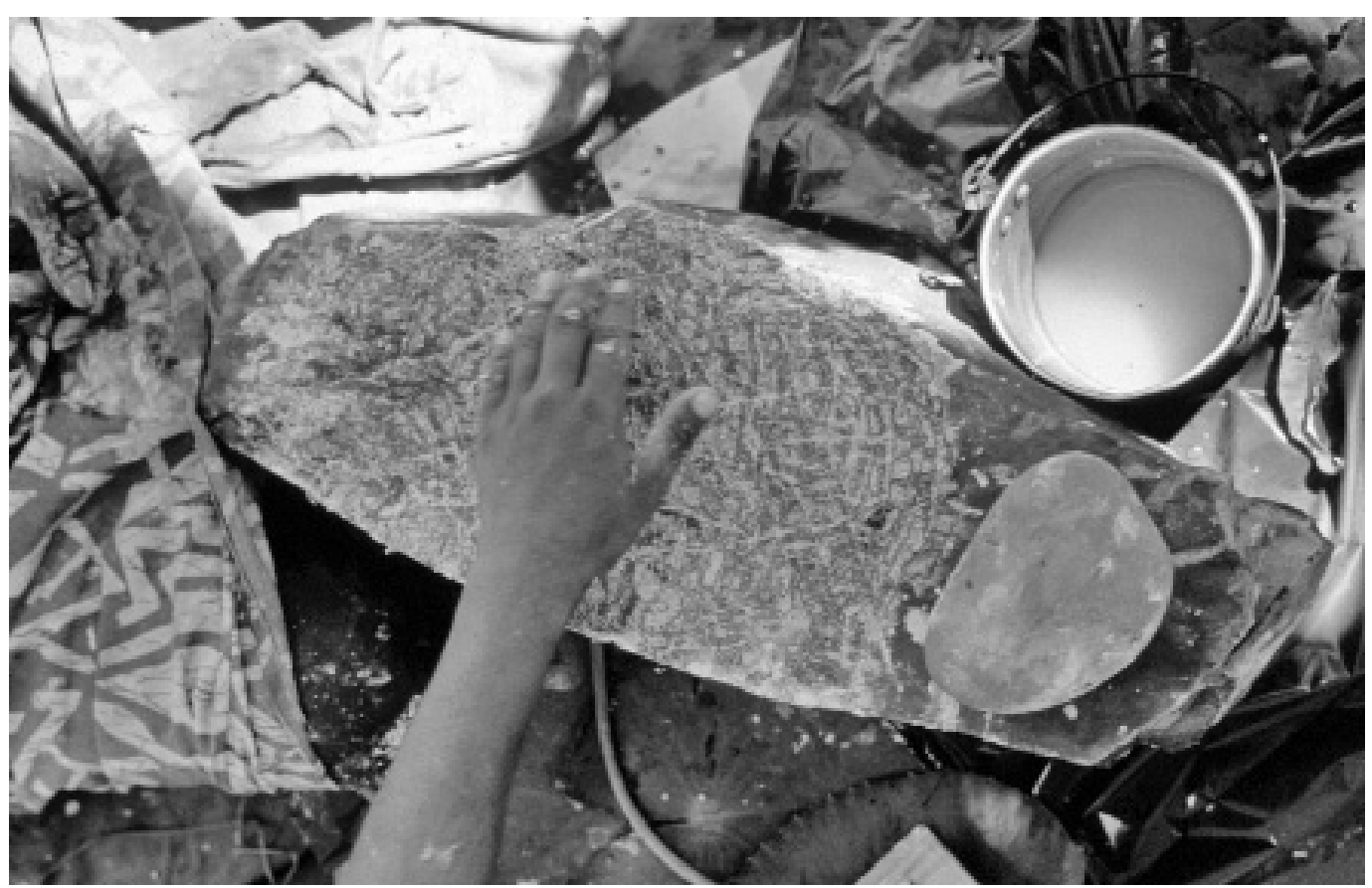

Figure 3. Biddy Simon processing water lily root in the Kimberley Region of north western Australia. She is using a sandstone grindstone with a small upper stone, or muller (to the right). The use of water in the milling of these seeds ensures that the starch paste is distributed over most surfaces and onto the surrounding ground surface. (Photo: Richard Fullagar/Lesley Head collection).

very small, they were not submitted for further processing (i.e. heavy liquid separation) in order to conserve the sample and reduce the loss of material. The water plus residue was centrifuged to concentrate the sample which was then were mounted on slides using either Permount or Karo mounting media. Slides were scanned for starch using a Zeiss Axioskop2 transmitted brightfield microscope with polarizing filters and Nomarksi optics. Images were captured using a Zeiss HRc digital camera and archived with Zeiss Axiovision software. 
The maximum length of all starch grains was measured (using the Axiovision software) and the results presented in a boxplot as counts per sample against the modern comparative reference collection. Maximum length has been determined as the best attribute for the initial filtering of results in order to exclude those species which have not contributed to the assemblage (Field and Lance, unpublished results). This is especially important when large comparative reference databases are being used and allows the analyst to quickly sort the material into a manageable form for further investigation. The North Queensland comparative starch reference collection is comprised of both field collected material and Herbarium voucher specimens, the latter courtesy of the Atherton Tropical Herbarium. Modern comparative reference materials were collected from a range of known economically important species from the Atherton Tablelands and the coastal strip south of Cairns (see Pedley 1993). In order to provide a representative sample of starch grains, the comparative sample consists, in most cases, of measurements (from $\geq 100$ granules) from three different specimens in order to document the range and variety of starches produced by each species.

\section{RESULTS}

Of the eleven morahs that were sampled for this analysis, one grindstone yielded no starch at all, while the remainder produced variable amounts of starch (Table 1; Figure 4). Five grindstones yielded over 30 grains each, allowing a very good estimate of the variability in the original population, assuming all extracted starch derives from a single taxon. Assuming an homogeneous sample, the estimate of the mean and variance is improved incrementally less as the sample size increases, and this commonly plateaus most noticeably around a sample size of 25-30.

Table 1. Starch grain counts from the eleven sampled grindstones

\begin{tabular}{|l|l|l|l|l|l|l|l|l|l|}
\hline CROATTO & & MAXWELL & & STAGER & & STAGER & & STAGER & \\
\hline Sample & $\mathrm{n}$ & Sample & $\mathrm{n}$ & Sample & $\mathrm{n}$ & Sample & $\mathrm{n}$ & Sample & $\mathrm{n}$ \\
\hline CU4/1 & 103 & WC G1/1 & 0 & $\mathrm{ST} 1 / 1$ & 0 & RS05031-1 & 11 & RS05035-1 & 0 \\
CU4/2 & 70 & WC G1/2 & 0 & ST1/2 & 1 & RS05031-2 & 15 & RS05035-2 & 12 \\
CU4/3 & 123 & & & & & RS05031-3 & 16 & RS05035-3 & 3 \\
\hline CR2/1 & 131 & & & ST2/1 & 0 & RS05032-1 & 3 & RS05034-1 & 0 \\
CR2/2 & 97 & & & ST2/2 & 1 & RS05032-2 & 13 & RS05034-2 & 3 \\
CR2/3 & 79 & & & ST2/3 & 0 & RS05032-3 & 31 & RS05034-3 & 0 \\
\hline
\end{tabular}

Of the three collections sampled, the Stager and Croatto material was productive, with the former providing variable counts. Of note are the two Croatto grindstones (CR2 and CU4) which yielded significant numbers of starch grains. Three of the Stager collection also produced significant numbers of starch grains (as a combined sample) and these were compared to the comparative reference collection for maximum size measurements. The maximum length of all starch grains was recorded and the results presented in a boxplot (Figures 5 and 6). Starch counts are shown above each grindstone sample number and for the individual species of reference material and are also presented in Table 1. The Croatto samples are consistent with B. bancroftii and E. insignis. While the whisker plots overlap with three other species, these are more likely to contribute only a small percentage of the sample, providing an indication of other species being processed. Some starch grains are very distinctive and require very few grains in order to estimate the likely species of origin - for example tubers and some grasses - however for the species likely to be represented here such as Cycas media and B. bancroftii the overlap in size and similarities in morphology demand a larger sample for examination (see Figure 7). 

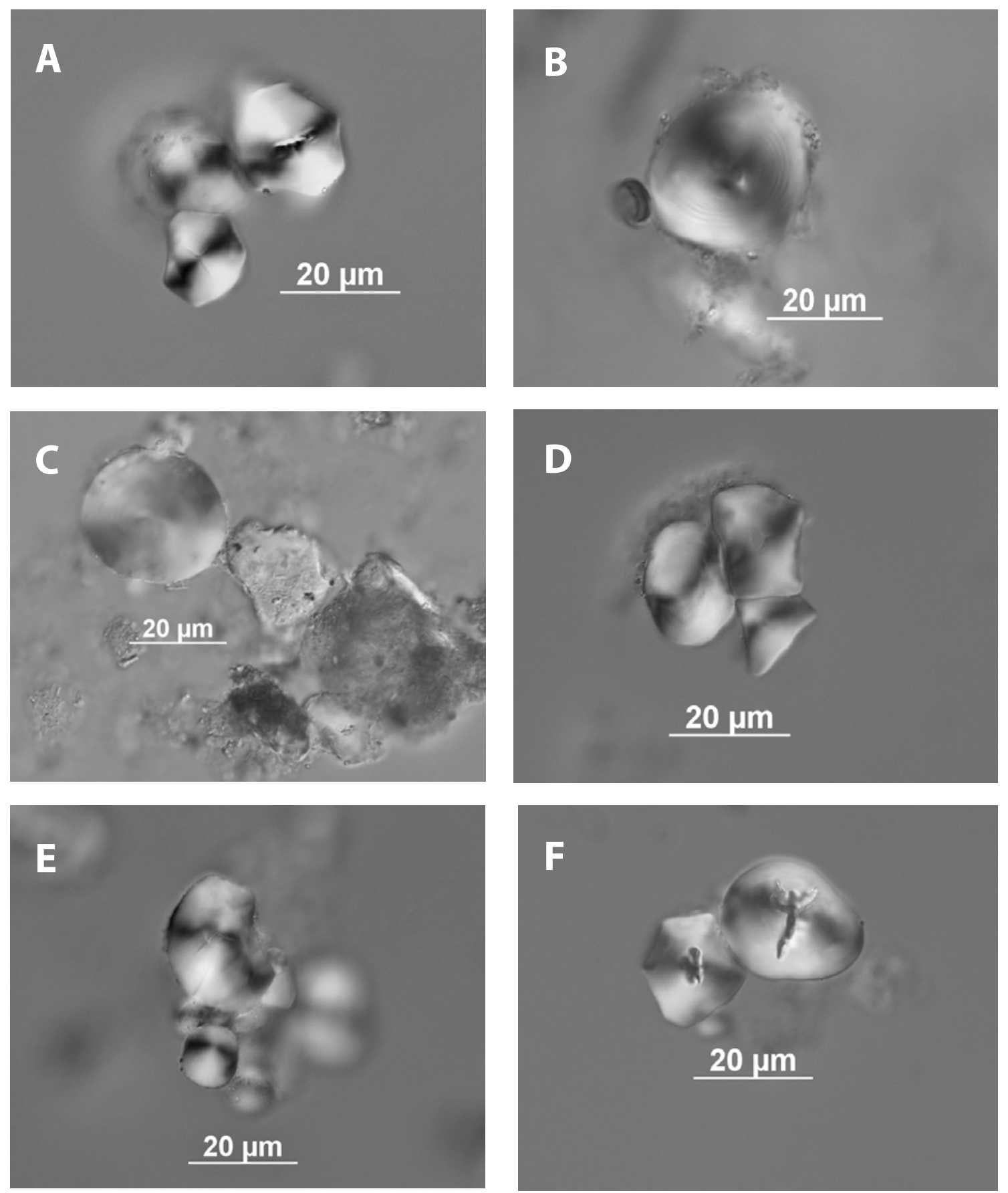

Figure 4. Starch grains identified on the surface of Morah grindstones which were sampled in private collections from North Queensland. A-D Stager Collection; E-F Croatto Grindstones. Many of the starch grains are facetted and some appear to exhibit damage from grinding. Fissures are also a common feature of many of the starch grains, e.g. F. Faceting and fissures at the hilum are common features of the Yellow Walnut and the Hairy Walnut. The processing of both species on these morahs is indicated by the maximum length measurements. All images collected on a Zeiss Axioskop II brightfield microscope with Nomarksi optics and a Zeiss HRc digital camera.

\section{DISCUSSION}

Grinding stones are durable formal tools that are commonly found as surface finds across the Australian continent. They are made of varying raw materials and, at least for sandstone grindstones, may be associated with restricted access quarries and traded for some considerable distances (McBryde 1997; Mulvaney 1998). Grinding stones are less common in the temperate margins of the Australian continent, except perhaps for far North Queensland rainforests where 


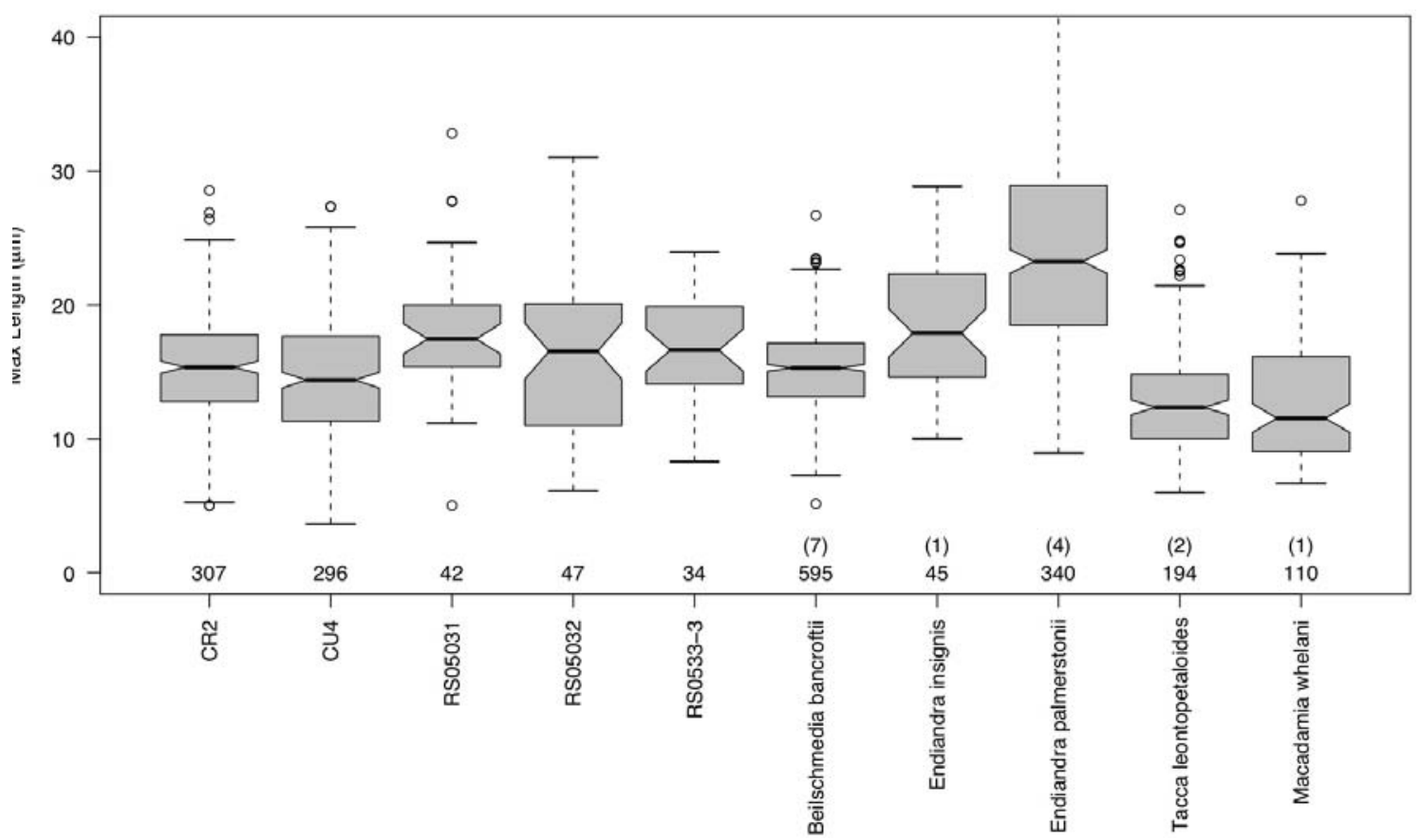

Figure 5. Boxplot of maximum lengths of starch for five morahs compared to modern reference collections. Note the two grindstones from the Croatto collection yielded significant starch counts, which are consistent with a predominant use of the Yellow Walnut, or Beilschmiedia bancroftii, but also falls within the parameters of the Hairy Walnut, Endiandra insignis.

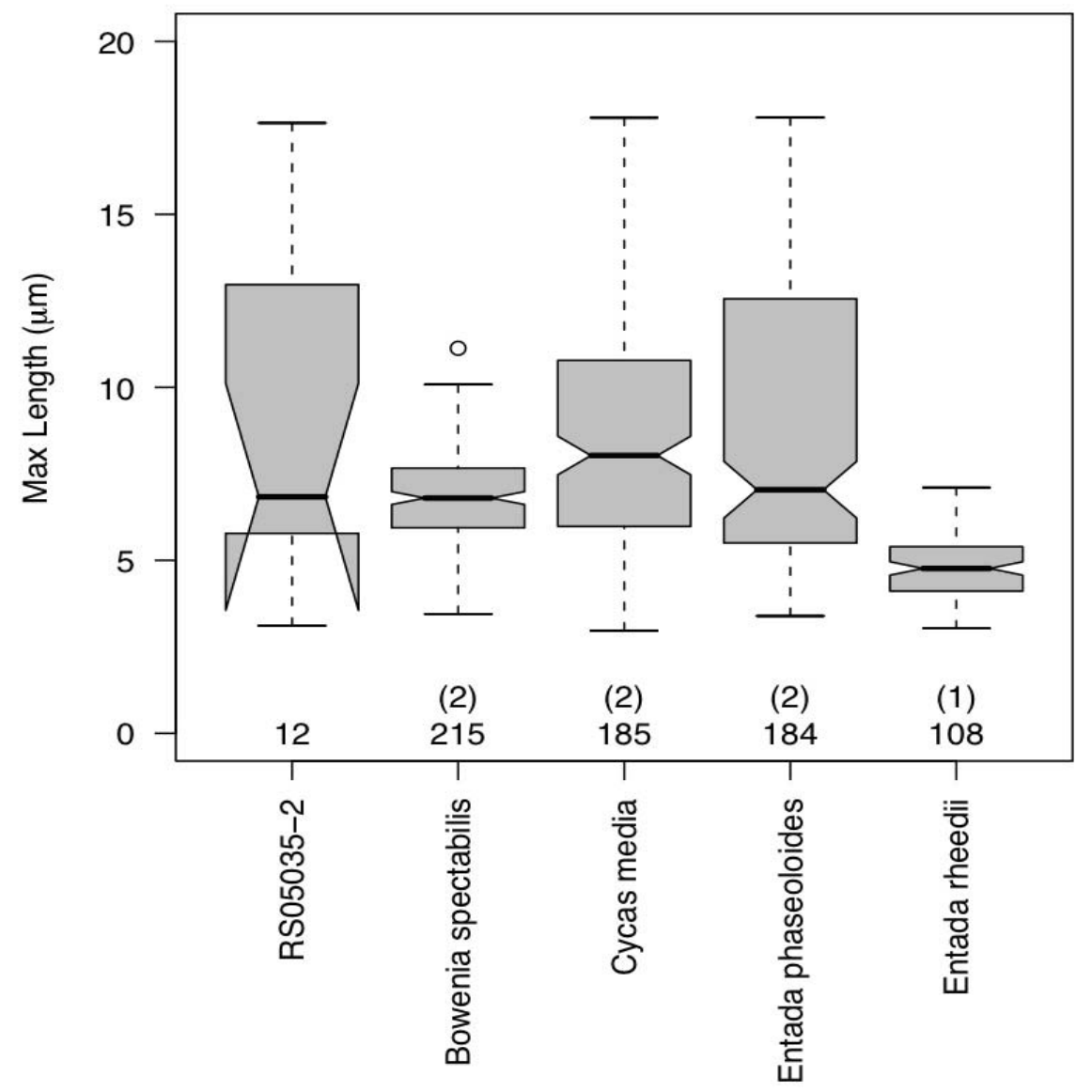

Figure 6. Boxplot of counts for a morah stone (RS05035-2) from the Stager collection. While the starch counts are low, the distinct difference in average size between this and those presented in Figure 5 indicated a different set of plants may have been processed with this implement, perhaps including one or all of those presented here. 

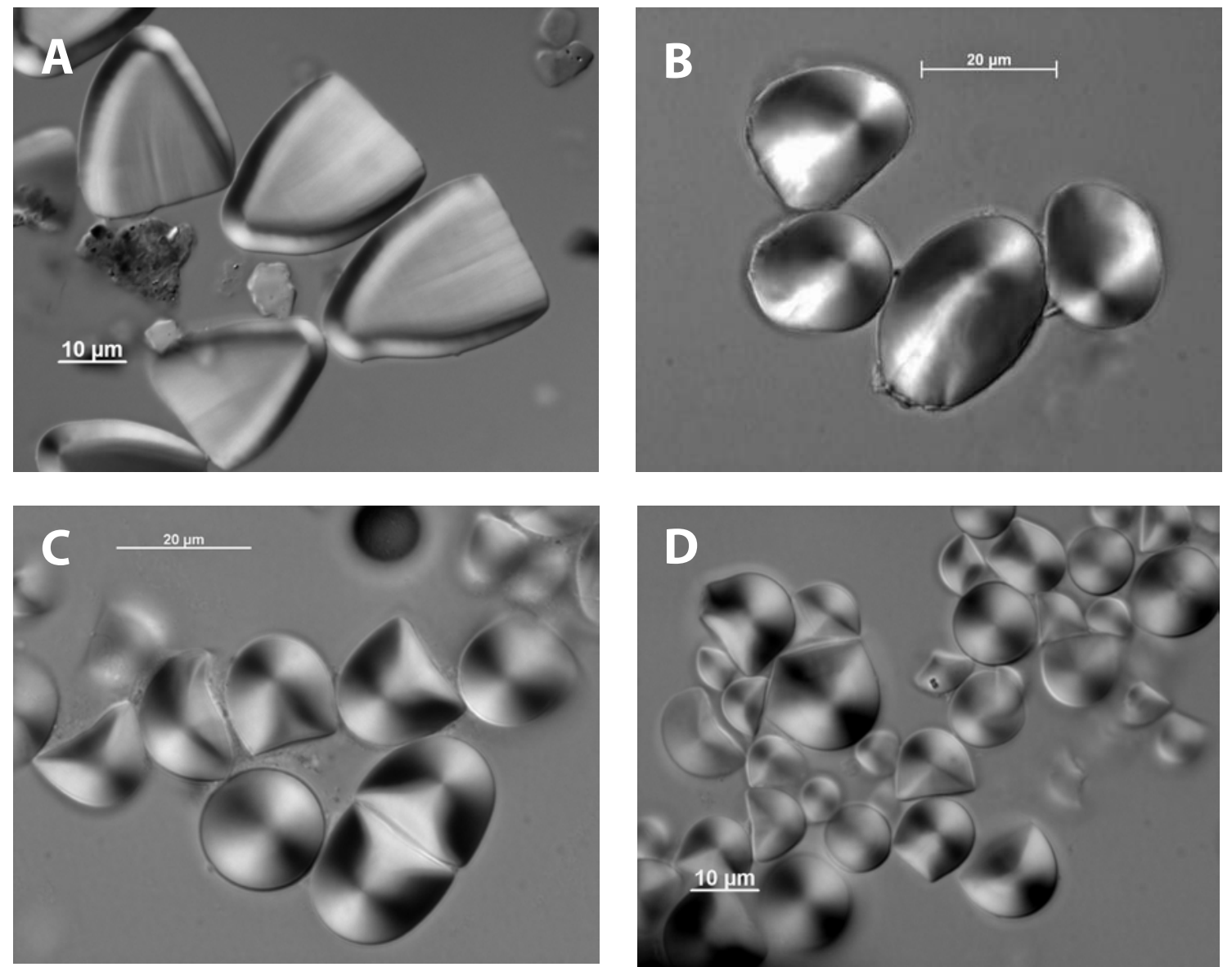

Figure 7. Examples of starch types from economically important plants of Far North Queensland rainforest and surrounds. A. Dioscorea bulbifera, or Hairy Yam, a tuber. B. Endiandra palmerstonii, Black Walnut, C. Beilschmiedia bancroftii, Yellow Walnut; D. Cycas media, Cycad. Note the morphological similarities between Cycas media and the Yellow walnut, though these can be separated on the basis of size measurements. (Photos: Nomarski optics with Axioskop 2 microscope and Zeiss HRc digital camera). (Photos: J. Field).

the morah or incised grinding stone is a common feature of the archaeological record (Cosgrove 1996; Cosgrove et al. 2007). Demonstrating their use for processing toxic starchy plants relies on the preservation of residue associated with use on the surfaces of these implements (see Cosgrove 2005; Harris 2006). Barton (2007) has reported the survival of starch on museum collections from tropical New Guinea, providing supporting data not only for the inferred use of particular artefacts, but also the survival of these microfossils in collections that are sometimes 'cleaned' and curated, not necessarily with the preservation of use-related residues in mind. In this study, the preservation of starch residues on morah stones held in private collections was investigated. These artefacts are generally stored on or adjacent to the locations where they were found and have not been curated or cleaned, as would perhaps occur in the museum collections described by Barton. The morahs examined here were found stacked together, covered in the sediment from which there were recovered and stored in 'dry' conditions.

This preliminary study was focussed on determining whether starch was preserved on the used surfaces of morah stones. The results are variable, but indicate that the residue traps provided by the incisions on the surface of morahs hold good potential for these types of studies. Combined with the morphology and associated use-wear patterns described below, there is compelling evidence to suggest that morah stones were used as grinding stones. On similar artefacts examined by Richard Fullagar, fine striations were found to occur at right angles to the incisions on the surface; they exhibit abrasive smoothing from grinding; and develop limited polish (polishes appear to develop on hard quartz grains within the stone matrix) - this is consistent 
with plant working. It has also been noted that undertaking use-wear studies on this type of stone is problematic as the raw material is very soft and residue films obscure the surface. Nonetheless, taken together, the morphology, residues and information about use-wear on similar implements are consistent with plant processing, in this case toxic starchy plants, most probably dominated by the Yellow Walnut (B. bancroftii) and also Hairy Walnut (E. insignis).

Establishing the use of morahs for the processing of toxic starchy plants has implications for our understanding of the timing and nature of permanent settlement of rainforest environments. Long term use of rainforest environments by people may hinge on access to a suite of toxic starchy plants (see Cosgrove et al. 2007). The development of the technologies for processing plants such as the Black Walnut, Yellow Walnut and Black Pine may have been transferred from the known methods for processing cycads, the antiquity of which has been reported as 13,000 years in Western Australia (Smith 1982, 1996). Cycas media is a common feature of the vegetation in the dry country on the margins of the rainforest, and the methods for processing these and the rainforest species are essentially the same - baking the starchy kernels for c. 6 hours followed by pounding to a paste, then leaching in running water for several days. The second step in this process, pounding to a paste, can also be achieved by grating with a shell (Pedley 1993).

In these studies, three separate lines of evidence are used to determine function (see Fullagar et al. 1996). Firstly, a technological study indicating that the morphology of morahs is typical of grinding stones - they are flat, with one or both surfaces showing evidence of use. The used surface is identified by the presence of concave areas where the surface has been worn down by continuous grinding. Peculiar to morahs are the incised parallel lines that run perpendicular to the maximum length of the stones.

Use-wear studies, the second stage in the functional analysis, indicate that these may have been made by quartz flakes as evidenced, by the sharp angular cuts and cross sectional characteristics. The raw material, slate, is a very soft stone and as such the incisions would have been relatively easy to produce. The incisions in the slate grindstones may serve the same purpose as the pecked surfaces observed on sandstone grindstones. In the latter case it is a method used to rejuvenate the grindstone surface to facilitate the breaking up of grass seed husks. The incised surfaces are always the used surfaces on the morahs.

The residue study which was the focus of this research has shown that the incised surfaces provided ideal locations for preservation/recovery of starch. Most of the artefacts sampled produced starch grains, though in greatly varying quantities. The variations may relate to the storage conditions of the morahs which were different in each case. Nonetheless the starch recovered has provided a clear indication of target species on the basis of maximum dimension measurements (see Lance et al. in press). While these stones appear to have been used for the processing of Yellow Walnuts and Hairy Walnuts, it is also clear that they were used to process other toxic nuts, perhaps as they became seasonally available. It is likely that these residues represent a record of the last use of the stones.

An interesting find is that the Stager grindstone, RS05035, was used to process a different set of plants to the other grindstones examined here, as indicated by the small sample of starch granules present on the stone surface. One of the species that may be present on this grindstone is Macadamia whelani. Pedley (1993:139) reports that no information was found in relation to the processing of $M$. whelani by Jirrbal-Girramay informants, nor from Murray Upper, near Tully, and it may not have been processed uniformly across the region where the morah stones are found. The identification of this plant as part of the assemblage on the Stager grindstone may be an indicator of detoxification closer to Babinda. A second species possibly identified on this stone, the Polynesian Arrowroot (Tacca leontopetaloides) is found on the coast in 'open forests and extends into rainforest behind sandy beaches' (Pedley 1993:117) and as such may act as an indicator of the location from which the stones are derived (i.e. coast as opposed to tablelands).

The identifications to plant species that are indicated in this study will need further corroboration by detailed analysis of the morphology of the starch, the degree of faceting and other surface features. 


\section{CONCLUSION}

Morah stones are used in the processing of toxic starchy nuts. This study has established that residues documented for these incised grinding stones are consistent with plant food processing, especially when the morphology and comparative data on use-wear patterns are taken into account. Comparison with modern reference materials indicates that these plants are likely to include $B$. bancroftii (Yellow Walnut) and Hairy Walnut (E. insignis). Other economic species may have contributed to the residue assemblage as it appears that these artefacts are unlikely to be single use and are of a size that is easily portable.

\section{ACKNOWLEDGEMENTS}

We would like to thank Maisie Barlow (Jirrbal), Pat and Alverio Croatto, Ned Maxwell, Deanna and Ron Stager for access to their private collections of morah stones. The Atherton Tropical Herbarium staff, especially Rebel Elick and Bruce Gray, helped us compile the plant/starch reference collections. Thanks to Don Page, Bernadette McCall and Anna Charlton for technical assistance. We are also grateful to Ernie Raymont (Ngatjin) for advice and support. The project was funded by an Australian Research Council Discovery Project grant, La Trobe University and the University of Sydney. We appreciated the constructive comments of Alison Crowther and Catherine Westcott. The authors acknowledge the facilities as well as scientific and technical assistance from the staff in the Australian Microscopy and Microanalysis Research Facility (AMMRF) and at the Australian Key Centre for Microscopy and Microanalysis at the University of Sydney.

\section{REFERENCES}

Barton, H. 2007. Starch residues on museum artefacts: implications for determining tool use. Journal of Archaeological Science 34:1752-1762.

Cosgrove, R. 1996. Past human use of rainforests: an Australasian perspective. Antiquity 70:900912.

Cosgrove, R. 2005. Coping with noxious nuts. Nature Australia 28(6):46-53.

Cosgrove, R., J. Field, and A. Ferrier 2007. The archaeology of Australia's tropical rainforests. Palaeogeography, Palaeoclimatology, Palaeoecology 251:150-173.

Ferrier, Å. 1999. A study of contact period Aboriginal material culture from the rainforest region of Northeast Queensland. Unpublished BA (Honours) thesis. Bundoora: Department of Archaeology, La Trobe University.

Field, J. and R. Fullagar 1998. Grinding and pounding stones from Cuddie Springs and Jinmium. In R. Fullagar (ed.) A Closer Look: Recent Australian Studies of Stone Tools, pp. 95-108. Sydney: Sydney University Archaeological Methods Series 6.

Fullagar, R. and J. Field 1997. Pleistocene seed grinding implements from the Australian arid zone. Antiquity 71:300-307.

Fullagar, R., J. Furby, and B. Hardy 1996. Residues on stone artefacts: state of a scientific art. Antiquity 70:740-745.

Fullagar, R., J. Field, and L. Kealhofer 2008. Grinding stones and seeds of change: starch and phytoliths as evidence of plant food processing. In Y. M. Rowan and J. R. Ebeling (eds) New Approaches to Old Stones: Recent Studies of Ground Stone Artifacts, pp. 159-172. London: Equinox Publishing P/L. 
Gould, R.A. 1980. Living Archaeology. Cambridge: Cambridge University Press.

Harris, D.R. 2006 The interplay of ethnographic and archaeological knowledge in the study of past human subsistence in the tropics. Journal of the Royal Anthropological Institute Special Issue. S63-S78.

Horsfall, N. 1987. Living in the rainforest: the prehistoric occupation of North Queensland's humid tropics. Unpublished PhD thesis. Townsville: James Cook University.

Lance, B., J. Field and R. Cosgrove In press. Intra-taxonomic variability in starch reference collections and the implications for ancient starch studies. In A. Fairbairn and S. O'Connor (eds) Proceedings of the 2005 Australasian Archaeometry Conference. Canberra: ANU E Press.

McBryde, I. 1997. 'The Landscape is a series of Stories'. Grindstones, quarries and exchange in Aboriginal Australia: a Lake Eyre case study. In A.Ramos-Millan and M.A. Bustillo (eds) Siliceous Rocks and Culture, pp. 587-607. Granada: University of Granada.

Mitchell, T.L. 1848. Journal of an Expedition into the Interior of Tropical Australia in Search of a Route from Sydney to the Gulf of Carpentaria. London: Longmans.

Mulvaney, K. 1998. The technology and Aboriginal association of a sandstone quarry near Helen Springs, N. Territory. In R. Fullagar (ed.) A Closer Look: Recent Australian Studies of Stone Tools, pp. 73-94. Sydney: Sydney University Archaeological Methods Series 6.

Pedley, H. 1993. Plant detoxification in the rainforest: The processing of poisonous plant foods by the Jirrbal-Girramay people. Unpublished M.A. thesis. Townsville: Material Culture Unit, James Cook University.

Smith, M. 1982. Late Pleistocene zamia exploitation in southern Western Australia. Archaeology in Oceania 17:109-116.

Smith, M. 1996. Revisiting Pleistocene Macrozamia. Australian Archaeology 42:52-53.

Smith, M.A. 1985. A morphological comparison of Central Australian seed-grinding implements and Australian Pleistocene-age grindstones. The Beagle, Occasional Papers of the Northern Territory Museum of Arts and Sciences 2(1): 23-38.

Tindale, N.B. 1977. Adaptive significance of the Panara or grass seed culture of Australia. In R.V.S. Wright (ed.) Stone tools as cultural markers: Change, evolution and complexity pp. 345-349. Canberra: Australian Institute of Aboriginal Studies.

Woolston, F.P. and F.S. Colliver 1973. Some stone artefacts from North Queensland rainforests. Occasional Papers in Anthropology 1:104-125. 